\title{
Ruptured intracranial dermoid cyst: a case report
}

\author{
Domenico Murrone*, Bruno Romanelli and Aldo Ierardi \\ Department of Neurosurgery, "Di Venere” City Hospital, Bari 70131, Italy
}

\begin{abstract}
Dermoid cysts are rare benign lesion of ectodermally origin containing dermal elements, including sebaceous glands, sweat glands, and hair follicles and rupture of dermoid cyst whit dissemination of intracystic content is very rare. We present a case of a 43-year-old female presented with head injury after a sudden loss of consciousness. Radiological examination showed an ovalar cystic lesion in left frontal region with hydrocephalus. A left frontal craniotomy for removal of the tumor was performed and histological examination revealed a dermoid cyst. We discuss the clinical and radiological feature and treatment of this case.
\end{abstract}

\begin{abstract}
Abbreviations: CT: computed tomography, MRI: magnetic resonance imaging

\section{Introduction}

Dermoid cysts are benign lesions of embryological origin that represent 0.04 to $0.6 \%$ of all intracranial tumors [1,2]. They arise from inclusion of ectodermally committed cells at the time of closure of the neural groove between the third and fifth week of embryonic life and are usually located in the midline and are found in the posterior fossa or suprasellar, fronto-basal, or temporo-basal regions. The cyst wall is characterized by a thick, stratified squamous epithelium capsule that contains dermal elements, including sebaceous glands, sweat glands, and hair follicles $[3,4]$. The presence of hair follicles and sebaceous and sweat glands in the cyst wall distinguishes dermoid from epidermoid cysts. Very rarely, these lesions may rupture and disseminate their intracystic contents into the subarachnoid space and ventricles [5]. We present a case of ruptured intracranial dermoid cyst, analyzing the clinical, pathological, and neuroimaging features and discussing the surgical management.
\end{abstract}

\section{Case report}

A 43-year-old woman with history of cognitive impairment and seizures, presented with head injury after a sudden loss of consciousness. Non-contrast Computed Tomography (CT) showed a mixed-density ovalar lesion in left frontal region with hypodense fatty portion and hyperdense areas of calcification, hypodense fat droplets in the left frontal lobe, in the left lateral ventricle and sylvian aqueduct with associated triventricular hydrocephalus T1-weighted Magnetic Resonance Imaging (MRI) scans demonstrated a heterogeneously hyperintense irregular lesion $(40 \mathrm{~mm}$ × $45 \mathrm{~mm} \times 27 \mathrm{~mm})$ with enhancement after gadolinium administration in the left frontal lobe with extension into the left lateral ventricle with hydrocephalus (Figure 1). The patient was administered anticonvulsant medication and underwent a left frontal craniotomy for removal of the tumor. Intraoperatively base of the tumor sited on the crista galli and fat droplets were visualized in the subarachnoid space. The cyst contents revealed fatty debris, cholesterinic liquid and calcifications. The tumor and cyst capsule were removed entirely. The disseminated fat droplets in the subarachnoid space and left lateral ventricle from the preoperative cyst rupture were left intact. Pathological analysis revealed a dermoid cyst with stratified squamous epithelium associated with adipose tissue, keratinous debris, calcific depositions and cholesterol crystals. Immunohistochemistry (CKAEE1/AE3, CD68PG-M1, CD34, MIB-1/Ki67) confirmed diagnosis of dermoid cyst. Postoperatively, the patient remained neurologically intact with an external ventricular drainage in the left lateral ventricle to eliminate fat droplets. In the tenth day after surgery the patient presented progressive headache and CT demonstrated worsening of hydrocephalus (Figure 2). The patient underwent a placement of right ventricular -peritoneal shunt with immediate improvement of headache. Her examination results remained stable at 1 year of follow-up.

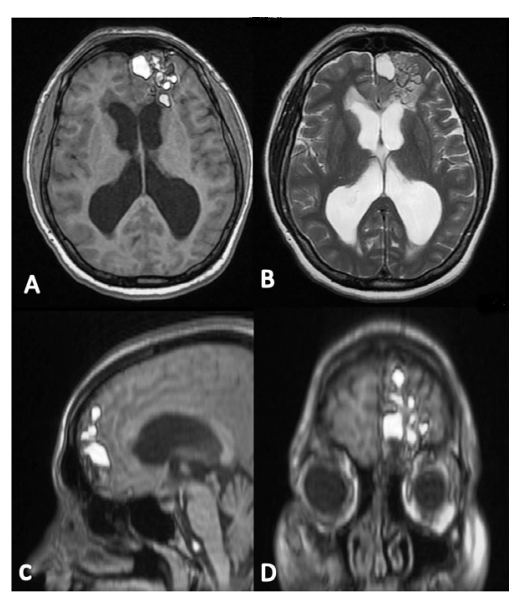

Figure 1. Axial (A), sagittal (C) and coronal (D) T1 weighted magnetic resonance (MR) revealing heterogeneously hyperintense irregular lesion with enhancement after gadolinium administration in the left frontal lobe with extension into the left lateral ventricle. Axial (B) $\mathrm{T} 2$ weighted magnetic resonance without contrast showing liquid intralesional content.

Correspondence to: Domenico Murrone, Department of Neurosurgery, "Di Venere" City Hospital, Bari 70131, Italy, E-mail: doflamingo82@gmail.com

Key words: dermoid cyst, ruptured dermoid cyst, intraventricular dissemination, surgical resection

Received: October 08, 2016; Accepted: October 17, 2016; Published: October 19,2016 


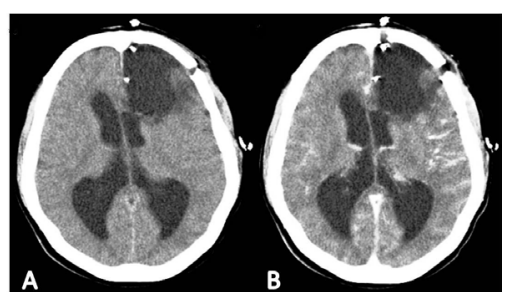

Figure 2. Post-operative axial without contrast (A) and with contrast (B) demonstrating total resection of lesion with initial worsening of hydrocephalus.

\section{Discussion}

Dermoid cysts can have mixed densities on CT scan with the fatty portion and fat droplets hypodenses, and areas of calcification hyperdense. Hydrocephalus may be present if there is rupture into the ventricular system and a fat-fluid level may be present [6]. MRI scan usually shows an hyperintense on T1-weighted images lesion with fat content but it sometimes can appear more heterogeneous with minimal enhancement because of the presence of calcifications, hair, epithelial debris, and sebaceous secretion. Disseminated lipid droplets in the subarachnoid cisterns or ventricles with a fat-fluid level appear hyperintense on T1-weighted images and are sensitive for the diagnosis of a ruptured dermoid cyst $[7,8]$. Rupture of intracranial epidermoid cysts is a very rare phenomenon. The rupture, usually spontaneous, can be happened after closed-head trauma [9]. The mechanism of rupture is unknown and Stendel et al. hypothesized that glandular secretions, possibly increased by age-dependent hormonal changes, may lead to rapid enlargement and rupture of these cysts [10]. The dissemination of intracystic contents, especially fat droplets, after surgical removal of dermoid cysts has also been described [8-11]. Approximately 51 cases have been described in the literature [5-19]. During a rupture of intracranial dermoid cysts into the subarachnoid space or ventricular system, patients can present aspecific symptoms, including headache, seizures, hemiparesis, aseptic meningitis, hydrocephalus, vasospasm, cerebral ischemia, fat embolism, and visual deficit. Lipid contents in the subarachnoid space causes chemical irritation of the adjacent neurovascular structures. El-Bahy et al. [12] demonstred headache was the most common symptom (32.6\%), followed by seizures (26.5\%), cerebral ischemia with sensory or motor deficit (16.3\%), and aseptic meningitis $(8.2 \%)$. In patients with unruptured dermoid cysts, the signs or symptoms result from compression of adjacent neurovascular structures. For patients with large symptomatic lesions or neurological deficit surgical resection is recommended. The goal of treatment involves complete surgical removal of the primary tumor capsule and intracystic contents. Because the dissemination of fat droplets is usually extensive bilaterally, it is usually not possible nor is it necessary to remove the disseminated fat droplets. Surgical steps of resection of dermoid cysts are incision of the capsule, internal debulking with removal of cyst contents and microsurgically dissection of the capsule from adherent or adjacent neurovascular structures. In many cases the dermoid capsules have a dense adherence to the brain parenchyma and vasculature and so a total removal is very difficult. In a report by Yasargil et al. [13] the authors chose not to radically dissect a capsule involving the aqueduct of Sylvius. Extensive irrigation of the resection bed and subarachnoid cisterns is recommended to minimize the risk of postoperative aseptic meningitis and delayed cerebral ischemic deficit $[14,15]$. Recurrence rate after subtotal resection of a dermoid cyst is extremely low and so the benefits of obtaining complete resection must be considered against the risks of causing neurological injury [12-15]. Intraventricular or subarachnoid fat may persist for years after the time of rupture because they does not seem to be resorbed [14-19].

\section{Conclusions}

Ruptured intracranial dermoid cysts are very rare and patients commonly present with headaches, seizures, and symptoms related to mass effect. The radiological features and the presence of disseminated fat droplets in the subarachnoid space or ventricles scans is diagnostic for a ruptured dermoid cyst. Gross total removal is recommended when possible and the recurrence is rare.

\section{Consent}

Written informed consent was obtained from the patient for publication of this case report and any accompanying images.

\section{Conflict of interest}

\section{None}

\section{References}

1. Arseni C, DÄ $f n \ddot{A} f$ fil $̈$ L, Constantinescu AI, Carp N, Decu P (1976) Cerebral dermoid tumours. Neurochirurgia (Stuttg) 19: 104-114. [Crossref]

2. Berger MS, Wilson CB (1985) Epidermoid cysts of the posterior fossa. J Neurosurg 62 214-219. [Crossref]

3. Abramson RC, Morawetz RB, Schlitt M (1989) Multiple complications from an intracranial epidermoid cyst: case report and literature review. Neurosurgery 24: 574 578. [Crossref]

4. Guidetti B, Gagliardi FM (1977) Epidermoid and dermoid cysts. Clinical evaluation and late surgical results. J Neurosurg 47: 12-18. [Crossref]

5. Carvalho GA, Cervio A, Matthies C, Samii M (2000) Subarachnoid fat dissemination after resection of a cerebellopontine angle dysontogenic cyst: Case report and review of the literature. Neurosurgery 47: 760-764.

6. Smith AS, Benson JE, Blaser SI, Mizushima A, Tarr RW, et al. (1991) Diagnosis of ruptured intracranial dermoid cyst: value MR over CT. AJNR Am J Neuroradiol 12: 175-180. [Crossref]

7. Nägele T, Klose U, Grodd W, Opitz H, Schick F, et al. (1996) Three-dimensional chemical shift-selective MRI of a ruptured intracranial dermoid cyst. Neuroradiology 38: 572 574. [Crossref]

8. Wilms G, Casselman J, Demaerel P, Plets C, De Haene I, et al. (1991) CT and MRI of ruptured intracranial dermoids. Neuroradiology 33: 149-151. [Crossref]

9. 9. Phillips WE, Martinez CR, Cahill DW (1994) Ruptured intracranial dermoid tumor secondary to closed head trauma. Computed tomography and magnetic resonance imaging. J Neuroimaging 4: 169-170.

10. Stendel R, Pietilä TA, Lehmann K, Kurth R, Suess O, et al. (2002) Ruptured intracranial dermoid cysts. Surg Neurol 57: 391-398. [Crossref]

11. Messori A, Polonara G, Serio A, Gambelli E, Salvolini U (2002) Expanding experience with spontaneous dermoid rupture in the MRI era: diagnosis and follow-up. Eur $J$ Radiol 43: 19-27. [Crossref]

12. El-Bahy K, Kotb A, Galal A, El-Hakim A (2006) Ruptured intracranial dermoid cysts. Acta Neurochir (Wien) 148: 457-462. [Crossref]

13. YaÅŸargil MG, Abernathey CD, Sarioglu AC (1989) Microneurosurgical treatmen of intracranial dermoid and epidermoid tumors. Neurosurgery 24: 561-567. [Crossref]

14. Lunardi P, Missori P, Rizzo A, Gagliardi FM (1989) Chemical meningitis in ruptured intracranial dermoid. Case report and review of the literature. Surg Neurol 32: 449-452. [Crossref]

15. Lunardi P, Missori P (1991) Supratentorial dermoid cysts. J Neurosurg 75: 262-266. [Crossref]

16. 16. Ecker RD, Atkinson JL, Nichols DA (2003) Delayed ischemic deficit after resection of a large intracranial dermoid: Case report and review of the literature. Neurosurgery 52:706-710.

17. Yoshimoto K, Nishio S, Suzuki S, Fukui M, Hasuo K (1997) Movable oil in the brain intracranial ruptured dermoid tumors. Case illustration. J Neurosurg 86: 734. [Crossref] 
18. Patkar D, Krishnan A, Patankar T, Prasad S, Shah J, et al. (1999) Ruptured intracranial dermoids: magnetic resonance imaging. J Postgrad Med 45: 49-52. [Crossref]
19. Stendel R, Pietilä TA, Lehmann K, Kurth R, Suess O, et al. (2002) Ruptured intracranial dermoid cysts. Surg Neurol 57: 391-398. [Crossref]

Copyright: $\odot 2016$ Murrone D. This is an open-access article distributed under the terms of the Creative Commons Attribution License, which permits unrestricted use, distribution, and reproduction in any medium, provided the original author and source are credited. 